\title{
Effect of Hot Isostatic Pressing and Rare-Earth Elements Addition on the Microstructure and Hardness on Inconel 718
}

H. M. Medrano-Prieto ${ }^{1}$, C.G. Garay-Reyes ${ }^{2}$, M.A. Ruiz-Esparza-Rodriguez ${ }^{2}$, I. Estrada-Guel ${ }^{2}$, J.C GuíaTello $^{2}$, G. Rodríguez-Cabriales ${ }^{2}$, A. Santos-Beltran ${ }^{1}$, J.S. Castro-Carmona ${ }^{3}$, H. Camacho-Montes ${ }^{4}$ and R. Martínez-Sánchez

${ }^{1}$ Universidad Tecnológica de Chihuahua Sur. Km. 3 Carretera Chihuahua-Aldama S/N, CP 31313, Chihuahua, Chih., México., Chihuahua, Chihuahua, Mexico, ${ }^{2}$ Centro de InvestigaciónenMaterialesAvanzados (CIMAV), Laboratorio Nacional de Nanotecnología, Miguel de Cervantes No. 120, CP 31136, Chihuahua, Chih., México., Chihuahua, Chihuahua, Mexico, ${ }^{3}$ Universidad Autónoma de Ciudad Juárez (UACJ), Av. Plutarco Elías Calles No. 1210 Fovissste Chamizal, CP 32310, Ciudad Juárez, Chih., México., Chihuahua, Chihuahua, Mexico, ${ }^{4}$ Universidad Autónoma de Ciudad Juárez (UACJ), Av. Plutarco Elías Calles No. 1210 Fovissste Chamizal, CP 32310, Ciudad Juárez, Chih., México., Cd. Juárez, Chihuahua, Mexico, ${ }^{5}$ Centro de InvestigaciónenMaterialesAvanzados (CIMAV) Laboratorio Nacional de Nanotecnología, Miguel de Cervantes No. 120, CP 31136, Chihuahua, Chih., México., Chihuahua, Chihuahua, Mexico

Inconel 718 superalloy is highly employed in high-temperature applications; its principal properties are high resistance to oxidation and excellent mechanical performance. Such alloys are generally used in aeronautics and aerospace engines, power generation, and the chemical industry [1-3]. Recent studies on the influence of rare-earth elements as rhenium, hafnium, tantalum, niobium, and ruthenium have enlarged to develop superalloys with higher microstructural properties and mechanical performance. Also, significant effects on microstructural and mechanical properties because of cerium and yttrium additions have been reported due to an increase in the lattice mismatch and the grain boundaries, furthermore, promotes modifications in carbides and eutectic phases. Nevertheless, the employment of rare-earth elements and Hot Isostatic Pressure (HIP) has not been widely investigated in Inconel 718, even though some studies have reported that the rare-earth elements additions and HIP are good candidates to improve the microstructural and mechanical properties [34]. Inconel 718 modified with rare-earth elements was fabricated by mechanical alloying (MA). Burr of commercial superalloy was employed as raw material, and a mixture of rare-earth $(\mathrm{Ce} / \mathrm{La}-50 / 50)$ was taken with a purity of $99 \%$ to produce alloys with contents of $0.1,0.2$, and $0.3 \mathrm{wt} \%$ of Ce/La. The alloys were manufactured by $5 \mathrm{~h}$ of milling time in a mill Spex 8000 . The milling device and milling media employed were made from hardened steel, and $\mathrm{N}$-heptane was used as a process control agent under an argon milling atmosphere. Powder mass $8.5 \mathrm{~g}$ and a ball-to-powder ratio of 5:1 were utilized. The powders compaction was made in a hydraulic press under a uniaxial compaction pressure of $1.56 \mathrm{GPa}$ for 5 minutes. The compacted samples were submitted to two sintering methods for your comparison, conventional sintering and sintering by the HIP. The first one was carried out at $1200{ }^{\circ} \mathrm{C}$ for $4 \mathrm{~h}$ with samples in vacuum-sealed quartz, and the second one at $1200{ }^{\circ} \mathrm{C}$ for $4 \mathrm{~h}$ under argon gas at 17400 psi. Both sintering conditions were solubilized at 980 ${ }^{\circ} \mathrm{C}$ for $1 \mathrm{~h}$ and quenched in water at room temperature and the two-step aging treatment were made at $720{ }^{\circ} \mathrm{C}$ for $8 \mathrm{~h}$, cooling at $55 \mathrm{C}$ to $620^{\circ} \mathrm{C}$ and holding at $620^{\circ} \mathrm{C}$ for $8 \mathrm{~h}$ before air cooling to room temperature. The microstructural characterization was carried out in a transmission electron microscope HITACHI 7700, and the hardness was measured in a Vickers microhardness tester LM300 AT. Figure 1 corresponds to a STEMEDS mapping, which illustrates the spatial distribution of $\mathrm{Ni}, \mathrm{Nb}, \mathrm{C}, \mathrm{Fe}, \mathrm{Cr}, \mathrm{Mo}, \mathrm{Ti}, \mathrm{Al}, \mathrm{Ce}$, and La elements in Inconel 718 alloy with $0.3 \mathrm{Ce} / \mathrm{La}(\mathrm{wt} \%)$ sintered by HIP after heat treatment. The figure shows a grain refined microstructure formed for oxides, carbides, and $\delta$-precipitates $(\mathrm{Ni} 3 \mathrm{Nb})$ and homogeneous dispersion of rare-earth elements. In the microhardness graph from Figure 2, a gradual increment as a function of the processing conditions is observed. The hardness peaks were obtained in the 0.2 and $0.3 \mathrm{Ce} / \mathrm{La}$ (wt. \%) alloys in the C.S and HIP, respectively, both in the aged condition. 


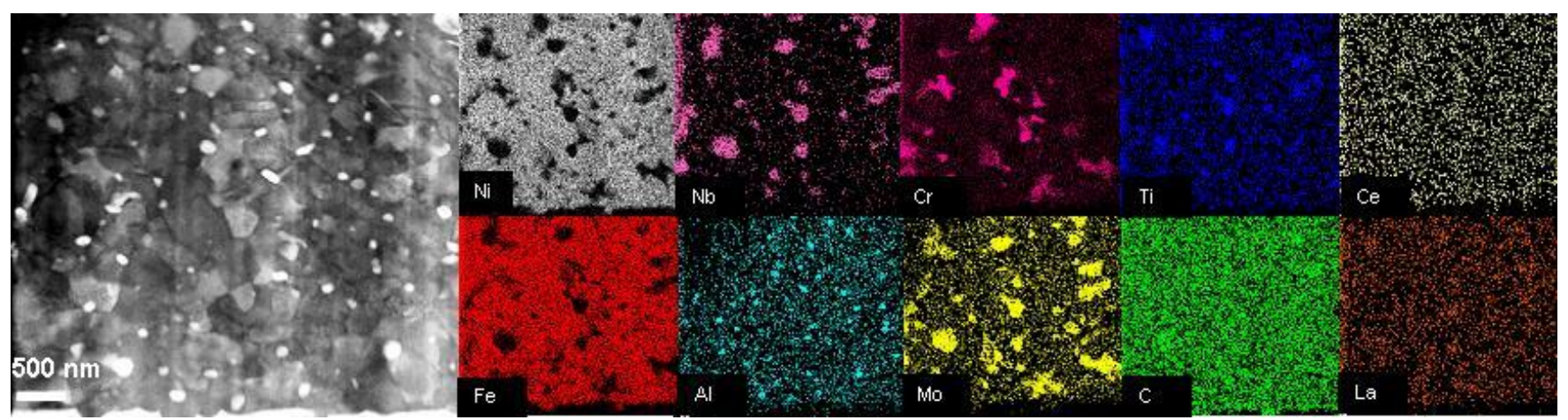

Figure 1. Figure. 1 STEM micrograph and its corresponding EDS elemental mapping in Inconel 718 with 0.3 rare-earth (wt. \%) content.

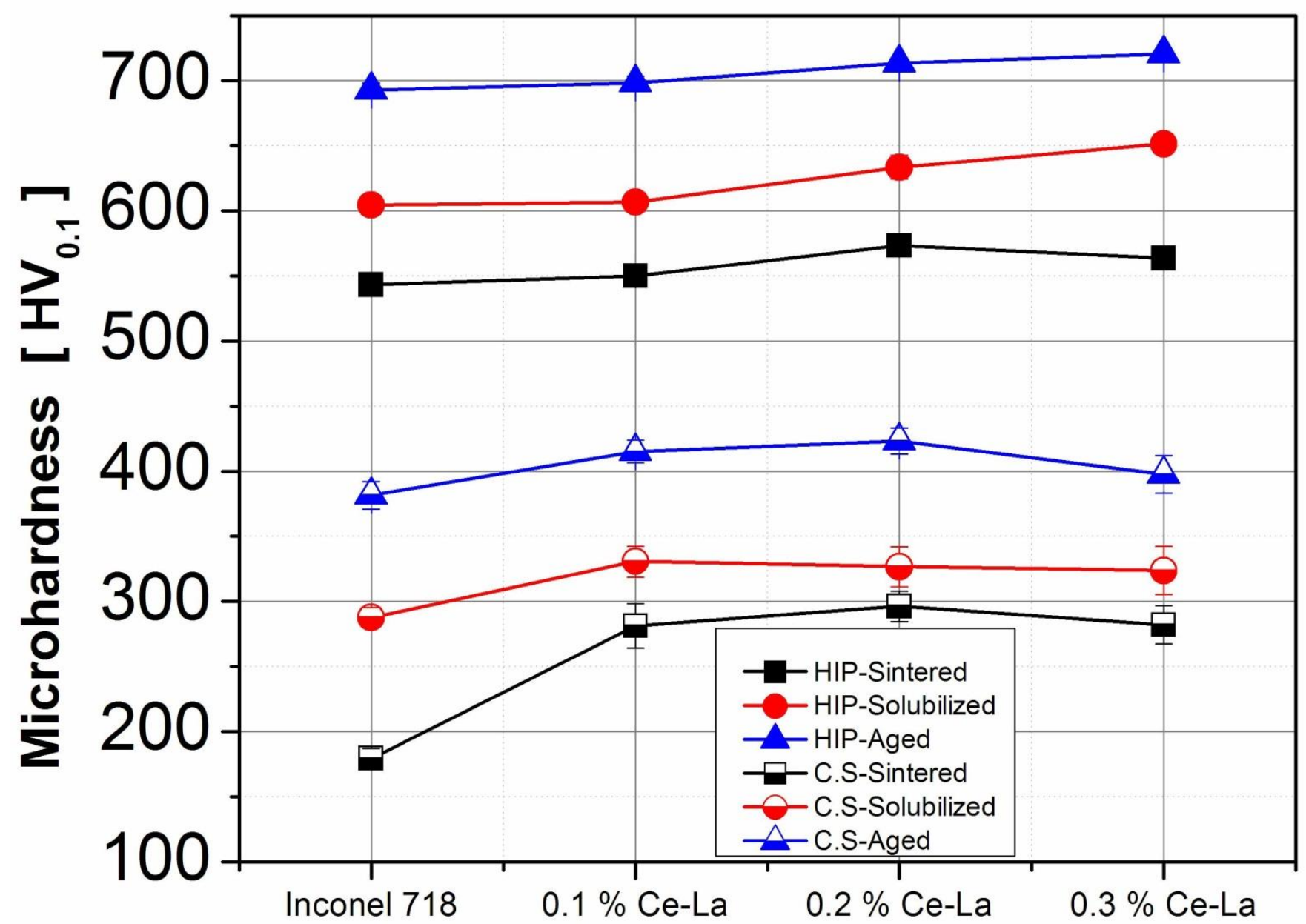

Figure 2. Figure. 2 Vickers microhardness values as a function of processing conditions for the Inconel 718 alloy and those alloys modified with rare-earth elements addition.

\section{References}

[1] E. Bassinia, V. Vola, M. Lorusso, R. Ghisleni, M. Lombardi, S. Biamino, D. Ugues, G. Vallillo, B. Picqué, Mater. Sci. Eng. A, 695 (2017) p. 55-65.

[2] Ming-Song Chen, Zong-Huai Zou, Y.C. Lin, Hong-Bin Li, Guan-Qiang Wang, Yan-Yong Ma, Mater. Charact, 151 (2019) p. 445-456. 
[3] G. Appa Rao, M. Srinivas, D.S. Sarma, Mater. Sci. Eng. A, 418 (2006) p. 282-291.

[4] T. Baskaran, Shashi Bhushan Arya, Ceram. Int, 44 (2018) p. 17695-17708. 